\section{RMD Open}

Rheumatic \&

Musculoskeletal Diseases

\title{
Are patients with rheumatic diseases on immunosuppressive therapies protected against preventable infections? A cross- sectional cohort study
}

\author{
Uta Kiltz (D) , ${ }^{1,2}$ Aylin Celik, ${ }^{3}$ Styliani Tsiami, ${ }^{1,2}$ Bjoern Buehring, ${ }^{1,2}$ \\ Xenofon Baraliakos (D) ,2 Ioana Andreica, ${ }^{1,2}$ David Kiefer, ${ }^{1,2}$ Juergen Braun ${ }^{1,2}$
}

To cite: Kiltz U, Celik A, Tsiami S, et al. Are patients with rheumatic diseases on immunosuppressive therapies protected against preventable infections? A cross-sectional cohort study. RMD Open 2021;7:e001499. doi:10.1136/ rmdopen-2020-001499

- Additional material is published online only. To view, please visit the journal online (http://dx.doi.org/10.1136/ rmdopen-2020-001499).

Received 28 0ctober 2020 Revised 25 February 2021 Accepted 23 March 2021
Check for updates

(c) Author(s) (or their employer(s)) 2021. Re-use permitted under CC BY-NC. No commercial re-use. See rights and permissions. Published by BMJ.

${ }^{1}$ Rheumatology, Rheumazentrum Ruhrgebiet, Herne, Germany ${ }^{2}$ Ruhr Universität Bochum Bochum, Germany ${ }^{3}$ Department of Internal Medicine, Klinikum Westfalen $\mathrm{GmbH}$, Dortmund, Germany

Correspondence to Uta Kiltz;

uta.kiltz@elisabethgruppe.de

\section{ABSTRACT}

Objective To evaluate the prevalence of infections, prevalence of hospitalisation due to infections, the vaccination status and perceived screening of infections prior to the start of biologic disease modifying antirheumatic drugs (bDMARDs) of a patient cohort with chronic inflammatory rheumatic diseases (CIRD).

Methods Consecutive CIRD patients reporting to our specialised centre were prospectively included $(n=975)$ in this cross-sectional study. Data on comorbidities including infections, treatment, vaccination status, screening for latent tuberculosis infection (LTBI) and hepatitis B (HepB) were collected. Antibodies against measles and HepB were measured by ELISA. The vaccination status was assessed by a predefined vaccination score $(0-26)$ categorising patients into four immunisation states: low (0-6), moderate (7-13), good (14-20), high (21-26).

Results All patients on bDMARDs $(n=499)$ were screened for LTBI, and 469 for HepB (94\%). All LTBI patients $(n=16)$ received isoniazid $(3.2 \%)$ and 16 chronic HepB patients received lamivudine (3.4\%). Protective measles specific IgG-antibodies were found in 901 patients (92.4\%). Although 629 patients were educated about vaccination strategies $(64.5 \%)$, only 540 showed a vaccination card (55.4\%). Only $49 \%$ of patients had undergone pneumococcal vaccination and less than $30 \%$ were protected against HepB and influenza, while $7.6 \%$ have not protective antibody titres against measles. No patient met the German national vaccination recommendations requiring a complete documentation of vaccines. The mean vaccination score was $13.3 \pm 4.2$ with $5.7 \%$ of patients having a low, $43.9 \%$ a moderate, $47.0 \%$ a good and $3.3 \%$ a high score.

Conclusions The majority of CIRD patients are not sufficiently vaccinated against pneumococci, HepB, influenza and measles. Although CIRD patients and general practitioners regularly receive professional information about the need of vaccination, vaccination rates were low to moderate. Interdisciplinary quality projects should be planned to change that inacceptable result.

\section{Key messages}

What is already known about this subject?

- Patients with chronic inflammatory rheumatic diseases (CIRD) have an increased risk of infections compared with the general population which is in part due to the disease but also due to immunosuppressive medication.

- Therefore, prevention of infections by vaccination strategies is important. In Germany general practitioners take care of vaccinations.

What does this study add?

- No CIRD patient met the German national vaccination recommendations that require a complete documentation of vaccinations given in childhood and adulthood.

How might this impact on clinical practice?

- Although CIRD patients and general practitioners regularly receive professional information about the need of vaccination, vaccination rates were low to moderate. Interdisciplinary quality projects should be planned to change that inacceptable result.

\section{INTRODUCTION}

Patients with chronic inflammatory rheumatic diseases (CIRD) are known to have an increased risk of infections compared with the general population. ${ }^{1}$ There are two main reasons for this risk: the burden of inflammation attributable to the disease itself and the immunosuppressive medication. Comorbidities and in advanced disease stages, sarcopenia and immobilisation contribute to the increased risk of infection. ${ }^{2}$ The vast majority of patients with CIRD are receiving therapies with glucocorticoids and disease modifying antirheumatic drugs (DMARDs), such as conventional synthetic DMARDs (csDMARDs) or biologic DMARDs (bDMARDs). Although the degree of immunosuppression may vary 
Table 1 Vaccine preventable infections

\begin{tabular}{|c|c|c|c|c|}
\hline Viral infections & Disease & Bacterial infections & Disease & $\begin{array}{l}\text { Toxin induced } \\
\text { diseases }\end{array}$ \\
\hline Measles virus & Measles & Pneumococci & Pneumonia & Tetanus toxin \\
\hline Mumps virus & Mumps & $\begin{array}{l}\text { Corynebacterium } \\
\text { diphtheriae }\end{array}$ & Diphtheria & Diphtheria toxin \\
\hline Rubella virus & Rubella & Bordetella pertussis & Whooping cough & \\
\hline $\begin{array}{l}\text { Variola major (human alpha } \\
\text { herpesvirus 3) }\end{array}$ & Chickenpox & Neisseria meningitidis & Meningitis & \\
\hline Varicella-zoster virus & Herpes zoster & Haemophilus influenzae b & $\begin{array}{l}\text { Pneumonia } \\
\text { meningitis }\end{array}$ & \\
\hline Human papillomavirus (HPV) & $\begin{array}{l}\text { Precancerosis, } \\
\text { cervical cancer }\end{array}$ & Salmonella typhimurium & Typhoid fever & \\
\hline Hepatitis A virus & Hepatitis A & & & \\
\hline Hepatitis B virus & Hepatitis B & & & \\
\hline SARS-CoV 2 & COVID-19 & & & \\
\hline Tick-borne encephalitis virus & $\begin{array}{l}\text { tTck-borne } \\
\text { encephalitis }\end{array}$ & & & \\
\hline Yellow fever virus & Yellow fever & & & \\
\hline
\end{tabular}

between different drugs, an increased risk of infections was especially described for bDMARDs and tDMARDs. ${ }^{3-5}$ Before treatment with bDMARDs can be started, screening for latent tuberculosis infection (LTBI) is mandatory in virtually all countries ${ }^{6}$ while screening for HepB (HepB) is also highly recommended before treatment-also because reactivation of HepB in patients on biologicals has not infrequently been observed. ${ }^{78}$

In a recent systematic literature search by European Alliance of Associations for Rheumatology (EULAR) about the incidence and prevalence of vaccine preventable infections (table 1), 63 relevant publications were identified that reveal an increased incidence of influenza and pneumococcal disease, while the herpes zoster (HZ) infection-pooled incidence rate ratio (IRR) was 2.9 and the human papillomavirus (HPV) infection-pooled prevalence ratio was 1.6 in patients with CIRD versus the general population. ${ }^{9}$ Thus, EULAR recommends that patients with CIRD should receive influenza, pneumococcal, tetanus toxoid and $\mathrm{HZ}$ vaccination. ${ }^{710}$ In the current corona pandemic we learnt once more how important effective and save strategies are needed to prevent patients at risk for infectious diseases. Interestingly, a protective effect of influenza vaccines might be manifest in patients with COVID-19. ${ }^{11}$ Marín-Hernández et $a l^{11}$ report that in patients with higher influenza vaccination rates less deaths from COVID-19 occurred in Italy.

The annual incidence of influenza in the general population is estimated as $5 \%-10 \%$ of adults, according to the WHO. ${ }^{12}$ One in 10 unvaccinated adults is estimated to be infected by seasonal influenza annually; with rates of symptomatic influenza roughly half of these estimates. ${ }^{13}$ The rates of influenza in the rheumatoid arthritis (RA) population compared with controls showed a significant IRR of 1.2-fold and a 2.75-fold increase in incidence of influenza-related complications in RA. ${ }^{14} \mathrm{~A}$ high risk for influenza and influenza-related complications in elderly patients ( $\geq 65$ years) with rheumatic diseases has been reported. ${ }^{14}$ Seasonal trivalent influenza vaccination is also associated with a reduced incidence of bacterial complications, hospital admissions and mortality in patients with RA and systemic lupus erthematosus (SLE). ${ }^{9}$

Pneumococcal pneumonia is the most common clinical presentation of pneumococcal disease and the most common cause of hospitalisation for community-acquired pneumonia in the adult population. ${ }^{15}$ The IRR for pneumococcal pneumonia in patients with RA compared with healthy controls is $4.4 .^{17}$ Since 1998 the incidence of invasive pneumococcal disease in the USA has significantly decreased from 100 to $9 / 100.000$ persons in 2015, following the implementation of a vaccination policy for pneumococcal disease. ${ }^{18}$

The prevalence of HepB infection in the CIRD population seems to be similar and in some studies even lower compared with the general population. ${ }^{19}$ Similarly, the pooled prevalence of HepB surface (HBs) antigen and HepB core antibody in patients with CIRD was found to be similar to the general population, with $3 \%$ and $15 \%$, respectively. ${ }^{9}$ Thus, reactivation of $\mathrm{HepB}$ is the main problem. ${ }^{20}$

The lifetime risk of developing $H Z$ in the general population is between $25 \%$ and $30 \%$, rising to $50 \%$ in those aged at least 80 years. $^{21}$ The estimated average overall incidence of $\mathrm{HZ}$ is about 3.4-4.8/1000 person years, increasing to more than $11 / 1000$ person years in those aged $\geq 80$ years. $^{22}$ In comparison to the general population, the risk of $\mathrm{HZ}$ infection in the CIRD population is increased with a pooled IRR 2.9. ${ }^{23}{ }^{24}$ However, since for long time only the live-attenuated zoster vaccine was 
available, prevention for $\mathrm{HZ}$ by vaccine was not possible for patients with CIRD.

One of the most important strategies to prevent certain infections is the consequent vaccination of all patients and a periodical check of the vaccination status. Thus, vaccinations against influenza, pneumococci and HepB are, next to the other regular vaccinations for tetanus, polio, pertussis and diphtheria, highly recommended for patients with CIRD in Germany. ${ }^{25}{ }^{26}$ Also, vaccination against measles has been recommended in Germany since 1970. However, because of a hesitant attitude towards vaccination in one part of the population, Germany has reported an insufficient uptake of measles vaccination. ${ }^{27}$ In contrast, measles were largely eradicated in the USA by 2000, but this does not seem to be the case anymore-due to too many exceptions not to vaccinate. ${ }^{28}$ The development of vaccine-preventable diseases makes it clear why and how well-founded the WHO has already declared vaccination hesitancy to be 1 of the 10 threats to global health in $2019 .{ }^{29}$ However, the advantages of consequent vaccination strategies are obvious. Vaccinations were proven immunogenic in the majority of studies in patients with CIRD, even when treated with immunosuppressive agents with the exclusion of B cell depletion. ${ }^{30}$ Although studies that are sufficiently powered with regard to safety are lacking, in the majority of studies, disease activity remained stable and only mild adverse events were reported, comparable with healthy controls. Therefore, the updated EULAR recommendations on vaccination clearly states that vaccination should strongly be considered for the vast majority of patients with CIRD. ${ }^{7}$

The aim of our study is to evaluate the prevalence of infections, prevalence of hospitalisation due to infections, vaccination status and perceived screening of infections prior to the start of bDMARDs in a patient cohort with CIRD.

\section{METHODS}

Population

This single-centre cross-sectional study was conducted in our tertiary rheumatology centre from December 2017 to October 2018. Consecutive patients with CIRD were prospectively recruited and participants gave written informed consent. Patient (eg, age, gender, education, place of birth) and disease characteristics (eg, disease type, disease duration, disease activity) were investigated at one time point. Information on previous infections, history of chronic recurrent infections including $\mathrm{HZ}$ virus infection, history of sepsis and history of hospitalisation due to an infection and vaccination status of the patient as well as data on comorbidities, current treatment and applied screening for LTBI and HepB were collected through a medical history interview and information from the hospital information system. Events happened before treatment in our hospital were used as self-report events and were not cross-checked with information from the hospital information system. Data were documented on standardised paper case report file. Place of birth outside of Germany were used to define being an immigrant. Screening for HepB included determination of surface antigen ( $\mathrm{HBsAg})$, surface antibody and cor antibody (AntiHBc). Latent $\mathrm{HepB}$ were defined in case of positive AntiHBc in the absence of HBsAg. In addition, antibodies against measles

were measured. Elevated CRP levels were used to define high disease activity. We assessed the risk of developing a serious infection by applying the RABBIT Risk Score in our cohort with CIRD patients. ${ }^{31}$ The RABBIT Risk Score calculates the probability of a patient with rheumatoid arthritis to develop a serious infection within the next 12 months. Higher percentages indicate a higher risk.

Based on clinical relevance, we decided to preferably check the situation related to potential protection against infections for which the general risk of infection has become practical in the sense of an established increased risk. This is clearly the case for influenza, pneumococcal infections, tuberculosis and HepB.

\section{Vaccination card}

The vaccination status was assessed by checking the vaccination cards in all patients. Patients who did not have the vaccination card ready at the study visit received a reminder letter to present the vaccination card on the next visit. All patients were asked whether they were educated about the importance of vaccination and by whom they received the information. Documentation of vaccination in the vaccination card was checked for the following vaccines: diphtheria, hepatitis B, influenza, measles, meningococcal, pertussis, pneumococcal, polio, rubella and tetanus toxoid. A vaccination has only been counted as such if documented in the international vaccination card. The only exception was the annual vaccination against influenza, as German law does not require documentation. Annual vaccination was defined as having received the vaccine during the last season. When we started this study, we decided not to check the HPV vaccination status of our patients because the majority of our patients is much older and the vaccine to prevent from HPV infections was not yet available. In addition, the inactivated vaccine against $\mathrm{HZ}$ was not available in Germany at the beginning of the study, so that the survey of the vaccination status was not performed.

\section{Vaccine recommendations}

Fulfilment of the German public health recommendation for vaccination and EULAR recommendations for vaccination of patients with autoimmune inflammatory rheumatic diseases was documented. ${ }^{10}$ Patients were classified as vaccinated according to the 2010 EULAR recommendations if they had a yearly influenza (influenza winter season 2017-2018), an every 5-year pneumococcal and a decennial tetanus toxoid vaccine, the latter as recommended in the general population. Fulfilment of vaccination status according to the 
Table 2 Variables of the immunisation score

\begin{tabular}{|c|c|c|c|}
\hline Vaccination & Vaccination status & Definition & Points \\
\hline \multirow[t]{3}{*}{ Tetanus } & Incomplete & $1-2$ vaccinations & 1 \\
\hline & $\begin{array}{l}\text { Basic immunisation, but no vaccine } \\
\text { uptake within the last } 10 \text { years }\end{array}$ & 3 vaccinations & 2 \\
\hline & Complete & $\begin{array}{l}\text { Basic immunisation not older than } 10 \text { years or basic } \\
\text { immunisation+booster in the last } 10 \text { years }\end{array}$ & 3 \\
\hline \multirow[t]{3}{*}{ Diphtheria } & Incomplete & $1-2$ vaccinations & 1 \\
\hline & $\begin{array}{l}\text { Basic immunisation, but no vaccine } \\
\text { uptake within the last } 10 \text { years }\end{array}$ & 3 vaccinations & 2 \\
\hline & Complete & $\begin{array}{l}\text { Basic immunisation not older than } 10 \text { years or basic } \\
\text { immunisation+booster in the last } 10 \text { years }\end{array}$ & 3 \\
\hline \multirow[t]{3}{*}{ Pertussis } & Incomplete & $1-2$ vaccinations in the childhood & 1 \\
\hline & $\begin{array}{l}\text { Basic immunisation, but no vaccine } \\
\text { uptake within the last } 10 \text { years }\end{array}$ & 3 vaccinations in childhood or 1 in adulthood & 2 \\
\hline & Complete & Basic immunisation+one booster immunisation & 3 \\
\hline \multirow[t]{3}{*}{ Poliomyelitis } & Incomplete & $1-2$ vaccinations & 1 \\
\hline & Basic immunisation & 3 vaccinations & 2 \\
\hline & Complete & One booster immunisation & 3 \\
\hline \multirow[t]{2}{*}{ Hepatitis B } & Incomplete & $1-2$ vaccinations & 1 \\
\hline & Complete & 3 vaccinations & 2 \\
\hline \multirow[t]{2}{*}{ Influenza } & $\begin{array}{l}\text { Incomplete, vaccine uptake but not } \\
\text { within the last year }\end{array}$ & Vaccination not in previous year & 1 \\
\hline & Vaccine uptake within the last year & Vaccination within previous year & 2 \\
\hline \multirow[t]{2}{*}{ Pneumococcal } & $\begin{array}{l}\text { Incomplete, vaccine uptake within the } \\
\text { last } 5 \text { years }\end{array}$ & Vaccination older than 6 years & 1 \\
\hline & $\begin{array}{l}\text { Complete, vaccine uptake within the } \\
\text { last } 5 \text { years }\end{array}$ & Vaccination not older than 6 years & 2 \\
\hline \multirow[t]{2}{*}{ Meningococcal } & Incomplete & Only one meningococcus type vaccined & 1 \\
\hline & Complete & $\begin{array}{l}\text { Meningoccus B vaccine+meningococcus ACWY } \\
\text { vaccine }\end{array}$ & 2 \\
\hline \multirow[t]{2}{*}{ Measles } & Incomplete & 1 vaccination in the childhood & 1 \\
\hline & complete or born before 1970 & $\begin{array}{l}\text { People born before } 1970 \text { or } 2 \text { vaccinations in } \\
\text { childhood or } 1 \text { vaccination in adulthood }\end{array}$ & 2 \\
\hline \multirow[t]{2}{*}{ Rubella } & Incomplete & 1 vaccination & 1 \\
\hline & complete or male & 2 vaccinations for women (men always complete) & 2 \\
\hline \multirow[t]{2}{*}{ Varicella } & Incomplete & 1 vaccination & 1 \\
\hline & Complete & 2 vaccinations & 2 \\
\hline
\end{tabular}

German public health recommendation were documented according the recommendations published in $2017 .{ }^{25}$ We defined a vaccination as being 'complete' when vaccination status was documented according to the German public health recommendation (see for more details table 2). ${ }^{25}$ Update of tetanus toxoid vaccination was assessed as a general proxy for vaccination uptake in the German population. Because of a general low and often incomplete vaccination uptake in the German population, we categorise patients according to their current vaccine uptake into basic immunisation, incomplete or complete uptake (table 2). This predefined but not validated vaccination score allowing us to assess a semi quantitative immunisation status. The vaccination score (range 0-26) categorises patients: 3 points for a complete vaccination, 2 points for a basic immunisation and 1 point for an incomplete vaccination status for tetanus, diphtheria, poliomyelitis or pertussis. For HepB, pneumococci, influenza, meningococci, measles, rubella and varicella 2 points were given for a complete and one point for an incomplete vaccination status. Finally, patients were categorised into four immunisation states: low (0-6), moderate, ${ }^{7-13} \operatorname{good}^{14-20}$ and high $^{21-26}$ (table 3 ). The exact definition of the vaccination score is shown in table 2. 
Table 3 Thresholds of the immunisation score

\begin{tabular}{cl}
\hline Points & Immunisation status \\
\hline $0-6$ & Low immunisation status \\
$7-13$ & Moderate immunisation status \\
$14-20$ & Good immunisation status \\
$21-26$ & High immunisation status \\
\hline
\end{tabular}

\section{Statistics}

Descriptive data are presented as absolute frequencies and percentages when referring to qualitative variables. Continuous variables were expressed as mean $\pm \mathrm{SD}$ or median with IQR (25\%-75\% range), where appropriate. Correlation coefficients were calculated with Spearman rank correlation coefficient. Correlation were considered low if $\leq 0.30$, moderate if $>0.30$ and $\leq 0.50$, high if $>0.50$ and $<0.80$ and very good if $\geq 0.8$. Linear regression models were used to examine the association between vaccination status (independent variable) and various patients' characteristics (dependent variable) adjusted for potential confounders (age, sex). A value of $\mathrm{p}<0.05$ was considered statistically significant.

\section{RESULTS}

In total, 975 CIRD patients (173 (17.7\% immigrants) were prospectively included in the study (table 4 ). The group consisted of $424(43.5 \%)$ patients with rheumatoid arthritis, $123(12.6 \%)$ with psoriatic arthritis, 145 $(14.9 \%)$ with axial spondyloarthritis and 41 (4.2\%) patients with systemic lupus erythematosus with a mean SD age of $55.3 \pm 15.5$ (range $18-90$ years). The majority of patients was on bDMARDs $(n=499(51.2 \%))$. All patients on bDMARDs were screened for LTBI and 469 also for HepB $(94 \%)$. Evidence of LTBI was found in only 16 patients who had all received prophylaxis with isoniazid.

Out of 48 patients $(4.9 \%)$ with a history of hepatitis B virus infection, all but one patient had a negative test for HepB virus surface antigen (HBsAg). This one patient was known to have chronic hepatitis with no viral replication in serial HBVDNA testings during bDMARD treatment. Another patient had occult HepBeing anti-HBc positive

Table 4 Patients characteristics

\begin{tabular}{|c|c|c|c|c|c|}
\hline Variables & $\begin{array}{l}\text { RA } \\
(n=424)\end{array}$ & axSpA $(n=145)$ & PsA $(n=132)$ & $\begin{array}{l}\text { SLE } \\
(n=41)\end{array}$ & $\begin{array}{l}\text { Other } \\
\text { diseases* } \\
(n=233)\end{array}$ \\
\hline Age, years, mean (SD) & $60.7(13.4)$ & $\begin{array}{l}43.7 \\
(12.4)\end{array}$ & $\begin{array}{l}51.3 \\
(12.7)\end{array}$ & $\begin{array}{l}48.4 \\
(17.6)\end{array}$ & $\begin{array}{l}56.1 \\
(16.9)\end{array}$ \\
\hline Gender, male, n (\%) & $137(32.3)$ & 95 (65.5) & $55(41.7)$ & $4(9.8)$ & $64(27.5)$ \\
\hline Disease duration, years, mean (SD) & $8.6((9.0)$ & $12.0(11.6)$ & $8.1(8.9)$ & $10.0(10.5)$ & $6.5(11.6)$ \\
\hline Prevalence of comorbidities, n (\%) & $307(72.4)$ & $78(53.8)$ & 73 (55.3) & $26(63.4)$ & $134(57.5)$ \\
\hline Rabbit risk score, mean (SD) & $4.4(5.0)$ & $4.7(2.8)$ & $3.3(3.4)$ & $2.4(9.4)$ & $4.0(9.4)$ \\
\hline Current use of bDMARDs, $n$ (\%) & $163(38.4)$ & $103(71.0)$ & $76(57.6)$ & $9(22.0)$ & $59(25.3)$ \\
\hline Physical function, $†$ mean (SD) & $\begin{array}{l}1.30(0.76) \\
n=355\end{array}$ & $\begin{array}{l}4.0 \\
(2.55), n=142\end{array}$ & $\begin{array}{l}1.28 \\
(0.68), n=97\end{array}$ & $\begin{array}{l}1.12 \\
(0.67), n=40\end{array}$ & $\begin{array}{l}1.03 \\
(0.69), n=211\end{array}$ \\
\hline CRP (mg/dL), median (IQR) & $\begin{array}{l}0.3 \\
(0.1-0.7) \\
n=421\end{array}$ & $\begin{array}{l}0.2 \\
(0.1-0.6)\end{array}$ & $\begin{array}{l}0.2 \\
(0.1-0.7) \\
n=131\end{array}$ & $\begin{array}{l}0.2 \\
(0.0-0.4)\end{array}$ & $\begin{array}{l}0.3 \\
(0.1-0.6) \\
n=225\end{array}$ \\
\hline Screening for latent hepatitis $\ddagger$, $(\%)$ & $202(94.4)$ & $104(92.0)$ & $80(93.0)$ & $9(81.8)$ & $74(92.5)$ \\
\hline Vaccination card available, n (\%) & $230(54.2)$ & $76(52.4)$ & $66(50.0)$ & 28 (68.3) & $140(60.1)$ \\
\hline Education about vaccination, n (\%) & $273(64.4)$ & $101(69.7)$ & $81(61.4)$ & $28(68.3)$ & $146(62.7)$ \\
\hline $\begin{array}{l}\text { Complete pneumococcal vaccination } \\
\text { status, } \mathrm{n}(\%)\end{array}$ & $129(30.4)$ & $33(22.8)$ & $26(19.7)$ & $12(29.3)$ & $66(28.3)$ \\
\hline $\begin{array}{l}\text { Complete influenza vaccination status, } \\
\mathrm{n}(\%)\end{array}$ & $85(20.0)$ & $17(11.7)$ & $20(15.2)$ & $8(19.5)$ & $50(21.5)$ \\
\hline $\begin{array}{l}\text { Complete hepatitis B vaccination status, } \\
n(\%)\end{array}$ & $36(8.5)$ & $26(17.9)$ & $13(9.8)$ & $10(24.4)$ & $37(15.9)$ \\
\hline Vaccination score, mean (SD) & $12.33(5.12)$ & $\begin{array}{l}13.67 \\
(4.83)\end{array}$ & $12.75(4.98)$ & $13.25(3.92)$ & $\begin{array}{l}13.17 \\
(4.65)\end{array}$ \\
\hline
\end{tabular}

*Diseases with a small incidence like vasculitis, connective tissue disease other than SLE, periodic fever syndromes.

†Physical function was assessed with HAQ except for axSpA patients where BASFI was used.

łIn patients with previous or current bDMARD use.

axSpa, axial spondyloarthritis; BASFI, Bath Ankylosing Spondylitis Function INdex; bDMARDs, biologic disease modifying antirheumatic drugs; CRP, C reactive protein; HAQ, health assessment questionnaire; IQR, interquartile range; PsA, psoriatic arthritis; RA, rheuamtoid arthritis; SLE, systemic lupus erythematosus. 
and anti-HBs and HBsAg negative with, however, a few copies of HBV-DNA. Five patients had an anti-HBc only status being anti-HBc positive but HBsAg and anti-HBs negative. A total of 16 patients received virostatic prophylaxis with mostly lamivudine $(33.4 \%)$ : one patient with chronic hepatitis, one patient with anti-HBc only status and the others with low anti-HBs titres. The median (IQR) anti-HBs titre was 158.1 (70.2-385.4) IU/L. However, based on the commonly accepted antibody titre cut-off of $100 \mathrm{IU} / \mathrm{L}, 64.3 \%$ were protected against HepB.

Seven hundred and eight $(72.6 \%)$ of our patients were born before 1970 and a total of 446 patients (45.7\%) reported having measles in their childhood, while 147 $(15.1 \%)$ reported not having had measles infection (total $\mathrm{n}=593)$, and $382(39.2 \%)$ could not provide any information at all in this regard. IgG antibodies against measles were determined in a total of 928 patients $(95.2 \%)$. Protective measles specific IgG-antibodies were found in 901 patients $(97.1 \%)$. The mean anti-measles IgG-antibody titre was $8183 \pm 5420 \mathrm{mIU} / \mathrm{ml}$ (range $330-26.000 \mathrm{mIU} / \mathrm{ml}$ ). In patients born after 1970, the measles antibody titre was lower than in patients born before 1970. The height and the range of the titres did not differ between diseases (detailed data shown in Kiltz et $\left.a \vec{l}^{2}\right)$. Borderline and negative titres were present in 15 and 12 patients, respectively (4.8\%). The majority of patients $(47 / 55)$ who were vaccinated at least two times according to vaccination cards had a protective measles titre $(85.4 \%)$. Of the 930 patients without documented measles vaccination or sufficient measles vaccination, 854 patients $(91.8 \%)$ had a protective measles titre.

Infections were rather common in our cohort. Reportedly, 74 patients were hospitalised due to an infection during the 12 months prior to the start of the study $(7.6 \%)$. During lifetime, 84 patients had experienced a sepsis $(8.6 \%)$ and 91 patients had ever been isolated due to an infection $(9.3 \%)$. A history of varicella zoster infection was noted in 141 patients $(14.5 \%)$ and $263 \mathrm{had}$ recurrent herpes simplex infections $(27.0 \%)$.

The RABBIT Risk Score were assessed in 714 patients with a mean score of $3.8 \pm 4.3$ (range $0-46.6$ ). Score in RA patients $(n=351)$ did not deviate from the entire population (table 4). The RABBIT Risk Score were not different between different levels of immunisation calculated on the predefined immunisation score: values vary between $3.8 \pm 3.5,4.2 \pm 4.4,4.6 \pm 5.9$ and $3.6 \pm 2.3$ in patients with a low, moderate, good and high immunisation state, respectively. RABBIT Risk Score did not correlate with the vaccination score $(r=-0.002)$ but showed a significant correlation with age $(\mathrm{r}=0.28)$ and disease duration $(\mathrm{r}=0.22)$.

Of all CIRD patients included, $540(55.4 \%)$ presented a vaccination card (83 (15.4\%) immigrants), 953 patients remembered a vaccination at least once in their life $(97.7 \%)$, and only 10 patients stated that they had never received any vaccination. In 540 patients with a vaccination card, 454 had been vaccinated within the last 10 years for tetanus toxoid $(84.1 \%$ ) followed by documented vaccination rates of $49.1 \%$ and $33.4 \%$ for pneumococci within the last 5 years and influenza in the last season. Vaccination against pneumococci was performed in almost all patients with 23-valent polysaccharide vaccine (PPSV23) vaccine (data not shown). Four hundred and twelve patients confirmed having received at least once an influenza vaccination without documentation in the vaccination card (which is allowed in Germany) and thus, gives a self-report prevalence of $76.3 \%$ of influenza vaccination in our cohort. Remarkably, complete documentation of a basic immunisation was only available for tetanus toxoid in 308 patients $(57.0 \%)$ but 146 patients did receive a booster vaccination with tetanus toxoid within the last 10 years. One hundred and twenty-two patients were sufficiently vaccinated against HepB while 157 received at least one $\mathrm{HepB}$ vaccination but did not complete the basic vaccination. The median (IQR) anti-HBs titre for patients who had a complete vaccination against $\mathrm{HepB}$ was $152.5(57.3-381.2) \mathrm{IU} / \mathrm{L}$. However, based on the commonly accepted antibody titre cut-off of $100 \mathrm{IU} / \mathrm{L}, 73.1 \%$ were protected against HepB. 201 patients with vaccination cards $(37.2 \%)$ had written documentation of measles vaccinations since birth. Of these, 94 patients had been vaccinated at least one time against measles (including 80 patients born after 1970). Of the 267 patients, who were born after 1970 , documented measles vaccinations were available in 133 patients $(49.8 \%)$, and this was not the case in 134 (50.2\%). Among the 143 patients born after 1970 with vaccination cards, measles vaccinations were available in 2 patients three measles vaccination (1.4\%), in 43 patients two measles vaccination $(30.1 \%)$ and in 35 patients one measles vaccination $(24.5 \%)$. However, the cohort also included a total of 14 patients who had been immunised against immunised against measles in adulthood (one patient with four vaccinations, one patient with three vaccinations, three patients with two vaccinations and nine patients with one vaccination).

For rates of diphtheria, meningococcal, pertussis, polio, rubella and Varizella (see online supplemental tables 1-3).

Thus, no patient met the German national vaccination recommendations that require a complete documentation of vaccinations given in childhood and adulthood. The compliance with EULAR recommendations was $12.7 \%$ for the total sample and $23.0 \%$ for patients with a vaccination card-this was based on 124 patients who had been vaccinated against influenza annually, pneumococcal and tetanus toxoid within the last 5 and 10 years, respectively. Of 416 patients with CIRD not vaccinated according to EULAR recommendations but with a vaccination card, 52 and 11 patients received two and one vaccination out of the three vaccinations required by EULAR, respectively. The mean vaccination score was $13.3 \pm 4.2$ with $5.7 \%$ of patients categorised having a low, $43.9 \%$ a moderate, $47.0 \%$ a good and $3.3 \%$ a high score. Univariable linear regression analysis showed that a low vaccination status was significantly associated with 
Table 5 Univariable and multivariable linear regression analysis of the association between vaccination status with patient's characteristics

\begin{tabular}{|c|c|c|c|c|}
\hline \multirow[b]{2}{*}{ Dependent variable } & \multirow{2}{*}{$\begin{array}{l}\text { Univariable analysis } \\
\beta(95 \% \mathrm{Cl})\end{array}$} & \multirow[b]{2}{*}{$P$ value } & \multirow{2}{*}{$\begin{array}{l}\text { Multivariable analysis } \\
\beta(95 \% \mathrm{CI})\end{array}$} & \multirow[b]{2}{*}{$P$ value } \\
\hline & & & & \\
\hline Education & $0.002(-1.027$ to 1.063$)$ & 0.972 & $0.070(-0.491$ to 2.222$)$ & 0.200 \\
\hline Immigrants & $-0.167(-2.955$ to -0.976$)$ & $<0.001$ & $-0.162(-3.316$ to -0.677$)$ & 0.003 \\
\hline Disease duration & $-0.059(-0.071$ to 0.013$)$ & 0.177 & $-0.068(-0.094$ to 0.022$)$ & 0.227 \\
\hline Comorbidities & $-0.052(-1.258$ to 0.300$)$ & 0.228 & $0.103(-0.219$ to 2.133$)$ & 0.110 \\
\hline Infection risk (RABBIT Risk Score) & $0.034(-0.064$ to 0.121$)$ & 0.540 & $0.840(-0.025$ to 0.165$)$ & 0.147 \\
\hline High disease activity & $-0.093(1.587$ to -0.077$)$ & 0.031 & $-0.129(-2.127$ to 0.183$)$ & 0.020 \\
\hline bDMARD use & $0.066(-0.122$ to -1.011$)$ & 0.124 & 0.036 (-0.449 to 0.870$)$ & 0.530 \\
\hline
\end{tabular}

ORs of variables associated with a vaccination status $<0.05$ are shown in bold.

bDMARD, biologic disease modifying antirheumatic drug.

higher age, high disease activity and being an immigrant (table 5). After adjustment for age and sex in multivariable linear regression analysis, low vaccination status remains to be associated with high disease activity and being an immigrant (table 5).

Although 629 patients had been educated about vaccination strategies $(64.5 \%)$, only the limited number of 540 patients were able to show a vaccination card (55.4\%). Patients received most often information from their general practitioners (GPs) $(n=497,79 \%)$, followed by rheumatologists $(\mathrm{n}=215(34.2 \%))$. Physician from other specialties $(n=32(5.1 \%))$ and/or members of public healthcare $(\mathrm{n}=26(4.1 \%))$ played a minor role in providing information about vaccinations. One hundred and forty-one patients stated that they were informed about the importance of vaccination by several disciplines.

\section{DISCUSSION}

The main result of this study is that a majority of patients with CIRD presenting to a large centre for rheumatic diseases in Germany are not sufficiently protected against vaccine preventable infections such as influenza, pneumococci and HepB and that a relevant amount of patients did suffer from infectious disease which have led to hospitalisation or which required isolation. In contrast, screening for tuberculosis and hepatitis have been successfully implemented in clinical routine. The strength of this study is its prospective nature and that we have made great efforts to have the vaccination card of the patients available.

We showed in this large prospective study that screening for LTBI and HepB is successfully implemented in our cohort. Screening for LTBI is mandatory in patients with CIRD prior to prescription of bDMARDs and it is the responsibility of the rheumatologist to document the test results and to prescribe a prophylaxis in case of evidence of LTBI. ${ }^{33}$ This finding is in line with the EULAR points to consider for reporting, screening for and preventing selected comorbidities in CIRD patients which stated that history of tuberculosis should be documented including prior results of chest X-ray, tuberculin skin test, interferon- $\gamma$ release assay and Bacillus Calmette-Guérin (BCG) vaccination and also history of serious infections, opportunistic infections and chronic viral infections should be documented. ${ }^{34}$ In the case of incomplete hepatitis vaccination status, we recommended in daily routine to complete the vaccination by the treating GP. Moreover, success of screening of infectious disease has been shown by our centre also in respect to the corona pandemic situation where we were able to show a quite low prevalence of COVID-19 diseases in our region. ${ }^{35}$ However, structure of screening for infections is clearly different from the responsibility to check vaccination status in patients with CIRD.

The vaccination strategy in Germany is based on cooperation with GPs. However, this strategy does not seem to work very well-as already reported some years ago in Germany and in other parts of the world. ${ }^{32}{ }^{36-38}$ Thus, the overall rate of successful vaccination was low to moderate although patients had received professional information about vaccine strategies. For example, vaccination against measles are having a poor update in Germany and accordingly, we showed in our high-risk cohort that up to $7.6 \%$ of the patients did not have a protective antibody titre. ${ }^{27} 32$ However, gaps also exist in intersectoral care, as information about vaccinations given is only available through a paper-based form of the vaccination card. In our study, only half of the patients were ultimately able to present the immunisation card, so that we were not able to document in all patients the vaccination status in our CIRD patients as it is recommended in the EULAR points to consider for reporting, screening for and preventing selected comorbidities. ${ }^{34}$

The application of vaccinations is only refinanced in the German health system if the GP follows the German public health recommendations for vaccination. ${ }^{25}$ However, those recommendations were published for the general population and did not refer to patients with special needs such as patients with CIRD. In 2019, the Robert Koch Institute in Germany issued a special statement on vaccinations for immunodeficient patients, 
making a clear recommendation for the administration of dead vaccines in patients with CIRD. ${ }^{25}$ It is hoped that this publication and accompanying publications on pneumococci and meningocococci will lead to more CIRD patients being vaccinated. For persons with immunodeficiency, the German authorities recommends sequential pneumococci vaccination with PCV13 followed by PPSV23 since 2016. ${ }^{39}$ However, this recommendation has not been implemented as our study impressively shows. The same picture of undersupply can be seen with vaccination against meningococcus. In our study only a small percentage of our patients received the recommended combination of Men B and ACWY ${ }^{40}$ Moreover, the results of the regression analyses underline that it is highly important to identify a risk population within the CIRD patients to provide information that is appropriate to the target group.

In the current pandemic, it has been shown that vaccination is effective not only against the causative pathogen but also against other pathogens. Recent reports on the possible protective effect of influenza vaccination with data shown that higher influenza vaccination rates were associated with less deaths from COVID-19 in Italy are important for these data and this discussion. ${ }^{11}$ Furthermore, a tetravalent inactivated influenza vaccine induced trained immunity in an established in-vitro model, resulting in improved responsiveness of immune cells to SARS-CoV-2 stimulation. ${ }^{41}$ Thus, there are many reasons to promote vaccination in people with arthritis.

There is doubt that immunosuppression is associated with an increased risk of infection which, however, differs according to the drug used. Thus, compared with traditional DMARDs, standard-dose bDMARDs (OR 1.31) and high-dose bDMARDs (1.90) were associated with an increased risk of serious infections, although low-dose bDMARDs (0.93) were not. The risk was lower in patients who were methotrexate naive compared with traditional DMARD-experienced or antitumour necrosis factor biological drug-experienced patients. The absolute increase in the number of serious infections per 1000 patients treated each year ranged from 6 for standarddose biological drugs to 55 for combination biological therapy, compared with traditional DMARDs. In our cohort we detected a high morbidity due to infectious disease. $7.6 \%$ were hospitalised during the last 12 months due to infections, $8.6 \%$ suffered from a sepsis during their lifetime and $9.3 \%$ had to be isolated due to infections. However, the majority of pathogens that led to a severe course (hospitalisation, sepsis, isolation) were not among the vaccine-preventable diseases.

In conclusion, effective prevention of vaccine preventable disease in immunosuppressed patients remains challenging. Vaccines are usually available in European countries. There is one current exception: both pneumococcal vaccines (Pneumococcal conjugate vaccine PCV13 and Pneumococcal polysaccharide vaccine PPSV23) are currently out of stock due to a recommendation of German authorities related to the current corona pandemic. We are convinced that there is substantial room for improving the healthcare system and its effectivity here. Interdisciplinary quality projects should be planned to change current management strategies. Thus, rheumatologists should be encouraged to vaccinate CIRD patients themselves and the healthcare system should make sure that the associated efforts are compensated for.

\section{Twitter loana Andreica @no twitter}

Acknowledgements We would like to thank Professor Dr Ulf Müller-Ladner (Department of Rheumatology \& Clinical Immunology, Kerckhoff Clinic, Bad Nauheim, Germany) for critically reviewing the manuscript.

Contributors All authors, namely UK, AC, ST, BB, XB, IA, DK and JB have made substantial contributions to (1) the conception or design of the study or to (2) the data acquisition, analysis or interpretation, to (3) drafting or revising the manuscript critically as well as to (4) final approval of the published version. All aforementioned authors have verified the underlying data. Agreement to be accountable for all aspects of the work ensure that questions related to the accuracy or integrity of any part of the work are appropriately investigated and resolved.

Funding This work was supported by Novartis Pharma, Germany, specifically parts of data acquisition. No other involvement was supported. No author or any other person involved in the project or in the manuscript preparation has been paid to write this article. All authors had full access to all data in the study and accept responsibility for its validity and submission for publication.

Competing interests None declared.

Patient consent for publication Not required.

Ethics approval This cohort study complies with the Declaration of Helsinki (Fortaleza/BR, 2013), ICH guidelines of Good Clinical Practice GCP and the respective applicable supranational, international, national and local regulations and norms. The locally appointed ethics committee of the Ruhr-Universität Bochum, Germany, has specifically approved this study and the research protocol. Written informed consent has been obtained from the subjects (or their legally authorised representative).

Provenance and peer review Not commissioned; externally peer reviewed.

Data availability statement Data are available upon reasonable request. Data sharing statement: Data from this study will be shared upon request. Contact the corresponding author for such inquiries. Data availability statement: The data underlying this article are available in the article and in its online supplementary material.

Author note This cohort study is reported according to the current version 4 of the STROBE statement.

Open access This is an open access article distributed in accordance with the Creative Commons Attribution Non Commercial (CC BY-NC 4.0) license, which permits others to distribute, remix, adapt, build upon this work non-commercially, and license their derivative works on different terms, provided the original work is properly cited, appropriate credit is given, any changes made indicated, and the use is non-commercial. See: http://creativecommons.org/licenses/by-nc/4.0/.

\section{ORCID iDs}

Uta Kiltz http://orcid.org/0000-0001-5668-4497

Xenofon Baraliakos http://orcid.org/0000-0002-9475-9362

\section{REFERENCES}

1 Doran MF, Crowson CS, Pond GR, et al. Frequency of infection in patients with rheumatoid arthritis compared with controls: a population-based study. Arthritis Rheum 2002;46:2287-93.

2 Subesinghe S, Rutherford Al, Byng-Maddick R, et al. Recurrent serious infections in patients with rheumatoid arthritis-results from the British Society for rheumatology biologics register. Rheumatology 2018;57:651-5.

3 van der Veen MJ, van der Heide A, Kruize AA, et al. Infection rate and use of antibiotics in patients with rheumatoid arthritis treated with methotrexate. Ann Rheum Dis 1994;53:224-8.

4 Singh JA, Cameron C, Noorbaloochi S, et al. Risk of serious infection in biological treatment of patients with rheumatoid arthritis: a systematic review and meta-analysis. Lancet 2015;386:258-65. 
5 Listing J, Strangfeld A, Kary S, et al. Infections in patients with rheumatoid arthritis treated with biologic agents. Arthritis Rheum 2005;52:3403-12.

6 Kahwati LC, Feltner C, Halpern M, et al. Primary care screening and treatment for latent tuberculosis infection in adults: evidence report and systematic review for the US preventive services Task force. JAMA 2016;316:970-83.

7 Furer V, Rondaan C, Heijstek MW, et al. 2019 update of EULAR recommendations for vaccination in adult patients with autoimmune inflammatory rheumatic diseases. Ann Rheum Dis 2020;79:39-52.

8 Koutsianas C, Thomas K, Vassilopoulos D. Reactivation of hepatitis $B$ virus infection in rheumatic diseases: risk and management considerations. Ther Adv Musculoskelet Dis 2020;12:1759720X2091264.

9 Furer V, Rondaan C, Heijstek M, et al. Incidence and prevalence of vaccine preventable infections in adult patients with autoimmune inflammatory rheumatic diseases (AIIRD): a systemic literature review Informing the 2019 update of the EULAR recommendations for vaccination in adult patients with AIIRD. RMD Open 2019;5:e001041.

10 van Assen S, Agmon-Levin N, Elkayam O, et al. EULAR recommendations for vaccination in adult patients with autoimmune inflammatory rheumatic diseases. Ann Rheum Dis 2011;70:414-22.

11 Marín-Hernández D, Schwartz RE, Nixon DF. Epidemiological evidence for association between higher influenza vaccine uptake in the elderly and lower COVID-19 deaths in Italy. J Med Virol 2021;93:64-65.

12 WHO. Seasonal inlfuenza, data and statistics. Available: http://www. euro.who.int/en/health-topics/communicable-diseases/influenza/ data-and-statistics2020

13 Somes MP, Turner RM, Dwyer LJ, et al. Estimating the annual attack rate of seasonal influenza among unvaccinated individuals: a systematic review and meta-analysis. Vaccine 2018;36:3199-207.

14 Blumentals WA, Arreglado A, Napalkov P, et al. Rheumatoid arthritis and the incidence of influenza and influenza-related complications: a retrospective cohort study. BMC Musculoskelet Disord 2012;13:158.

15 Carratalà J, Mykietiuk A, Fernández-Sabé N, et al. Health careassociated pneumonia requiring hospital admission: epidemiology, antibiotic therapy, and clinical outcomes. Arch Intern Med 2007;167:1393-9.

16 Marrie TJ, Durant H, Yates L. Community-Acquired pneumonia requiring hospitalization: 5-year prospective study. Rev Infect Dis 1989;11:586-99.

17 Shea KM, Edelsberg J, Weycker D, et al. Rates of pneumococca disease in adults with chronic medical conditions. Open Forum Infect Dis 2014;1:ofu024.

18 Centers for Disease Control and Prevention. Pneumococcal disease: surveillance and reporting; 2020.

19 Sui M, Wu R, Hu X, et al. Low prevalence of hepatitis B virus infection in patients with autoimmune diseases in a Chinese patient population. J Viral Hepat 2014;21:925-9.

20 Chen $\mathrm{M}-\mathrm{H}$, Chen $\mathrm{M}-\mathrm{H}$, Liu C-Y, et al. Hepatitis B virus reactivation in rheumatoid arthritis patients undergoing biologics treatment. $J$ Infect Dis 2017;215:566-73.

21 Johnson RW, Alvarez-Pasquin M-J, Bijl M, et al. Herpes zoster epidemiology, management, and disease and economic burden in Europe: a multidisciplinary perspective. Ther Adv Vaccines 2015;3:109-20.

22 Marra F, Chong M, Najafzadeh M. Increasing incidence associated with herpes zoster infection in British Columbia, Canada. BMC Infect Dis 2016;16:589.

23 Thomas SL, Hall AJ. What does epidemiology tell us about risk factors for herpes zoster? Lancet Infect Dis 2004;4:26-33.

24 Mareque M, Oyagüez I, Morano R, et al. Systematic review of the evidence on the epidemiology of herpes zoster: incidence in the general population and specific subpopulations in Spain. Public Health 2019;167:136-46.

25 Robert Koch Institute. Recommendations of the Standing Vaccination Commission (STIKO) at the Robert Koch Institute 2017/2018]. Epid Bull 2017;34:333-80

26 Wagner N, Assmus F, Arendt G. Impfen bei Immundefizienz : Anwendungshinweise zu den von der Ständigen Impfkommission empfohlenen Impfungen. (IV) Impfen bei Autoimmunkrankheiten, bei anderen chronisch-entzündlichen Erkrankungen und unter immunmodulatorischer Therapie. Bundesgesundheitsblatt Gesundheitsforschung Gesundheitsschutz 2019;62:494-515.

27 Storr C, Sanftenberg L, Schelling J, et al. Measles Status-Barriers to vaccination and strategies for overcoming them. Dtsch Arztebl Int 2018;115:723-30.

28 Phadke VK, Bednarczyk RA, Salmon DA, et al. Association between vaccine refusal and vaccine-preventable diseases in the United States: a review of measles and pertussis. JAMA 2016;315:1149-58.

29 WHO. Ten threats to global health in 2019. Available: https://www. who.int/news-room/spotlight/ten-threats-to-global-health-in20192019

30 Rondaan C, Furer V, Heijstek MW, et al. Efficacy, immunogenicity and safety of vaccination in adult patients with autoimmune inflammatory rheumatic diseases: a systematic literature review for the 2019 update of EULAR recommendations. RMD Open 2019;5:e001035.

31 Zink A, Manger B, Kaufmann J, et al. Evaluation of the rabbit risk score for serious infections. Ann Rheum Dis 2014;73:1673-6.

32 Kiltz U, Celik A, Tsiami S. [How well are patients with chronic inflammatory rheumatic diseases protected against measles?]. $Z$ Rheumatol 2020.

33 Diel R, Hauer B, Loddenkemper R, et al. [Recommendations for tuberculosis screening before initiation of TNF-alpha-inhibitor treatment in rheumatic diseases]. Pneumologie 2009;63:329-34.

34 Baillet A, Gossec L, Carmona L, et al. Points to consider for reporting, screening for and preventing selected comorbidities in chronic inflammatory rheumatic diseases in daily practice: a EULAR initiative. Ann Rheum Dis 2016;75:965-73.

35 Andreica I, Kiefer D, Rezniczek GA, et al. Comment on 'Characteristics associated with hospitalisation for COVID-19 in people with rheumatic disease: data from the COVID-19 global rheumatology alliance physician-reported registry' by Gianfrancesco M et al. Ann Rheum Dis 2020. doi:10.1136/ annrheumdis-2020-218609. [Epub ahead of print: 30 Jul 2020].

36 Fendler C, Saracbasi E, Dybowski F, et al. [Practical problems by implementation of vaccination recommendations]. Z Rheumatol 2012;71:147-50, 153-5.

37 Feuchtenberger M, Kleinert S, Schwab S, et al. Vaccination survey in patients with rheumatoid arthritis: a cross-sectional study. Rheumatol Int 2012;32:1533-9.

38 Hmamouchi I, Winthrop K, Launay O, et al. Low rate of influenza and pneumococcal vaccine coverage in rheumatoid arthritis: data from the International COMORA cohort. Vaccine 2015;33:1446-52.

39 Robert-Koch-Institute. Scientific Justification for updating the recommendations for the vaccination against pneumococcus for risk groups. Epid Bull 2016;37:385-406.

40 Robert-Koch-Institute. Update of the meningococcal vaccine recommendation: use of the meningococcal $B$ vaccine in persons at increased risk of meningococcal disease. Epid Bull 2015;37:393-410.

41 Debisarun PA, Struycken P, Domínguez-Andrés J. The effect of influenza vaccination on trained immunity: impact on 2 COVID-19. medRxiv preprint 2020. 